\title{
IDIOPATHIC PULMONARY HAEMOSIDEROSIS IN AN ADULT
}

\author{
BY \\ N. WYNN-WILLIAMS AND R. DOUGLAS YOUNG
}

From the Bedford General Hospital

(RECEIVED FOR PUBLICATION DECEMBER 2, 1955)

First described by Ceelen (1931) idiopathic pulmonary haemosiderosis was thought to be a disease confined to children until Waldenström in 1940 reported the case of a patient aged 15 . We have been able to find 50 cases in the literature of which 15 have been in adults ( 15 years or older) at the time of diagnosis. One case, confirmed by biopsy, is added here, making a total of 16 adults.

\section{CASE Report}

A motor mechanic, born on July 17,1926 , was first seen at the Bedford Chest Clinic in November, 1952, as a contact of his father-in-law who had active pulmonary tuberculosis. He complained of lassitude but had no cough. His only significant previous illness was left-sided pleurisy in 1947. On clinical examination no abnormality was found. The chest radiograph revealed only a slightly enlarged left hilar shadow which was attributed to a large pulmonary vessel rather than a lymph node. An intradermal tuberculin test with $1 / 10,000$ old tuberculin was positive (11 mm. induration); blood count, erythrocyte sedimentation rate (E.S.R.), and plasma proteins were all within normal limits.

In July, 1953, he developed a left-sided pleurisy. A radiograph showed obliteration of the left costophrenic angle. As he also complained of severe headache he was admitted to hospital for investigation. The cerebrospinal fluid (C.S.F.) was normal, the blood sugar $70 \mathrm{mg}$. per $100 \mathrm{ml}$. and a blood count revealed red blood cells (R.B.C.) 4,800,000 per c.mm., haemoglobin (Hb) $98 \%$, white blood cells (W.B.C.) 10,600 per c.mm. with a normal differential count. The E.S.R. was $4 \mathrm{~mm}$. in the first hour. The Wassermann reaction (W.R.) in blood and C.S.F. was negative. The cause of his headache was found to be chronic frontal sinusitis. Within two weeks the chest film had returned to normal.

On January 21, 1955, he was readmitted to hospital with a history of increasing lassitude, dyspnoea on exertion, and one episode of vomiting a little blood. He also stated that he had coughed up some bright red blood. On examination he was found to be anaemic. There were no enlarged lymph nodes, the liver and spleen were not palpable, there was no abdominal tenderness but he had one small bleeding pile. Blood examination revealed R.B.C. 3,600,000 per c.mm., Hb $50 \%$, W.B.C. 7,200 per c.mm. with a normal differential count, packed cell volume $27 \%$, mean corpuscular volume $75.0 \mathrm{c} \mu$., mean corpuscular $\mathrm{Hb} 20.5 \mu \mu \mathrm{g}$, mean cell $\mathrm{Hb}$ concentration $27.4 \%$, and mean cell diameter $7.5 \mu$. The Van den Bergh reaction was less than 1 unit, the red cell fragility normal and the Wassermann reaction negative. A sternal marrow biopsy revealed a remarkably cellular marrow in which the primitive white cells were rather more numerous than the early red cells. There seemed to be no abnormality in the granular series. The early red cells showed slight "left shift" and a few megaloblasts were seen. There were a few plasma and reticular cells but not in significant numbers. There was no free iron in the smear. A barium meal revealed gastritis and a duodenal erosion. No radiograph of the chest was taken, but one on December 2, 1954, had been normal. He was treated with iron and a transfusion of 2 pints of blood. A reticulocyte response up to $3 \%$ occurred. He was discharged after 16 days with a blood count of R.B.C. $4,250,000$ per c.mm., and $\mathrm{Hb} 72 \%$.

On June 9, 1955, he attended for a routine chest radiograph which revealed fine nodular stippling over the lower half of each lung field (Fig. 1). A blood count showed R.B.C. 5,000,000 per c.mm., Hb $84 \%$, and W.B.C. 6,600 per c.mm. The E.S.R. was $3 \mathrm{~mm}$. in the first hour, the plasma proteins $6.75 \mathrm{~g} . \%$, and the blood urea was $28 \mathrm{mg}$.\%. He had no symptoms at that time but the following day began to have small repeated haemoptyses. Radiographs on June 14 and 23 showed no change in the lung fields and by June 23 blood tests revealed the following: R.B.C. $4.050,000$ per c.mm., Hb $75 \%$, W.B.C. 7,600 per c.mm. with a normal differential, and a platelet count of 340,200 per c.mm. The E.S.R. was $5 \mathrm{~mm}$. in the first hour, bleeding time and clotting time normal, and no lupus erythematosus cells were seen on the smear. Three specimens of sputum were submitted for haemosiderin examination and haemosiderin-laden phagocytes were found in large numbers. A diagnosis of idiopathic pulmonary haemosiderosis was made, the patient then being 28 years old.

In July he was admitted to the Brompton Hospital under the care of Dr. F. P. Lee Lander for further investigation. A left lung biopsy was carried out on August 2. Macroscopically, the lung was of an unusually bluish colour with patches of fawn mott- 
ling. It felt normal on palpation, with no nodularity. A wedge of tissue was taken from the anterior basal segment where the mottling was most profuse. The histological report was as follows:

"Haemosiderin - la de n macrophages are present in large numbers in all parts of the lung tissue (Figs. 2 and 3). Many alveoli are consolidated by these cells which give a strongly positive reaction for iron (Fig. 4). The alveolar walls show variable thickening due to cellular proliferation and increase in the reticulin framework (Fig. 5). This process has not proceeded to fibrosis. Few capillaries can be seen in the alveolar walls; arterioles and arteries show little abnormality ; no frank haemorrhage is visible. Occasional granulomatous follicles composed of plasma cells and giant cells are present. The appearances are consistent with idiopathic pulmonary haemosiderosis."

The report of a liver biopsy was as follows: "The liver tissue appears normal. No haemosiderin or other iron pigment is visible and there is no evidence of hepatic venous congestion or centrilobular fatty change." Values for serum proteins, alkaline phosphatase, thymol turbidity, and serum bilirubin were all normal. A test for cold agglutinins and a direct Coombs test were negative. $\mathrm{He}$ was treated with oral iron until October, by which time the blood count was normal. The radiographic appearances have remained unchanged up to November, 1955.

This patient had another episode of anaemia and stained sputum in February, 1956. He recovered from the anaemia, but the pulmonary nodulation has increased over the right lower zone.

\section{Comments on Reported CASES}

Table I presents certain details of 16 patients with idiopathic pulmonary haemosiderosis described in adults. Twelve of them have been men, which suggests that the condition is commoner in men than in women, although the sex incidence in children appears equal. Diagnosis has been made most frequently on clinical and radiological evidence, but was confirmed at necropsy in five and by lung biopsy in two. At the time of symp- $\frac{7}{0}$ toms first leading to a chest radiograph there was no radiological abnormality in six out of $10 \mathrm{~N}$ patients in whom there is adequate information on $\mathrm{N}$ this point. Moreover in the patient described by N Tait and Corridan (1952) there was no radiological abnormality at the time of death.

It is too early to be sure whether the prognosis of the disease in adults is as bad as that in children, $\mathbb{D}$ but reference to Table I shows that the prognosis is very serious. Two patients are reported alive after four years' observation ; the rest are dead or have only been followed for short periods.

\section{Discussion}

It is likely that idiopathic pulmonary haemosiderosis in adults is commoner than the few pub- 


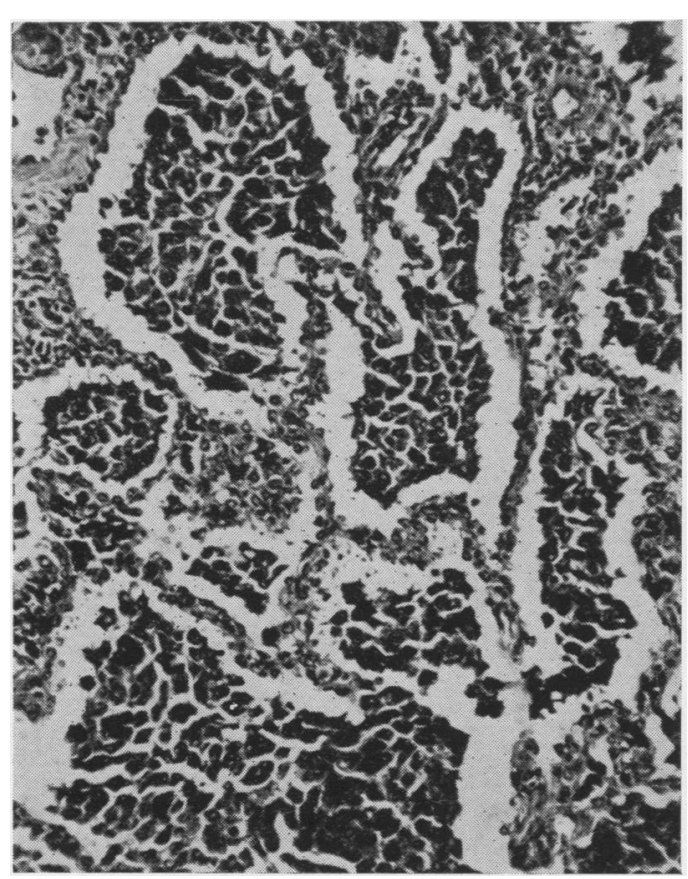

FIG. 2.-Alveoli containing Imacrophages heavily loaded with haemosiderin. The alveolar walls are thickened by cellular proliferation and contain small deposits of haemosiderin. Haematoxylin and eosin, $\times 120$.

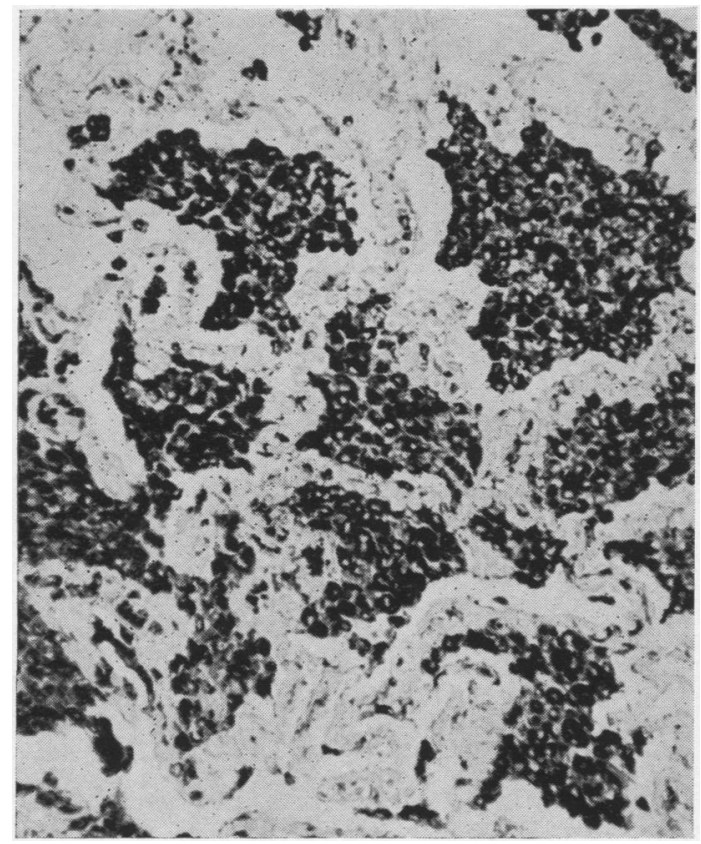

Fig. 4.-A similar field to that in Fig. 2. The section shows an intense, diffuse Prussian-blue reaction in the cytoplasm of the intra-alveolar macrophages. Perles' ferrocyanide reaction, $\times 120$.

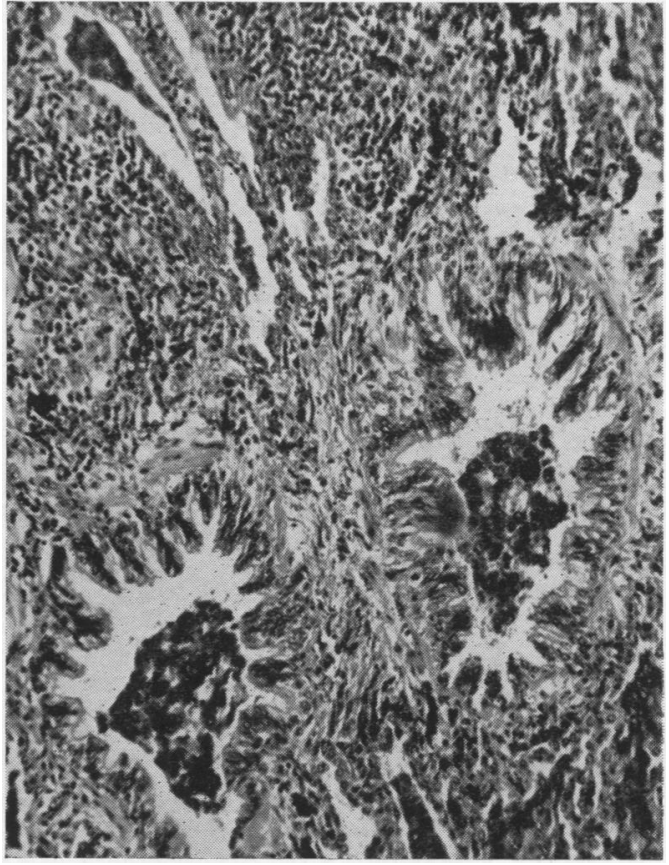

Fig. 3.-Two bronchioles and a lymphatic (top left) containing macrophages loaded with haemosiderin. Similar macrophages lying in collapsed alveoli can be seen in the lower part of the field. Haematoxylin and eosin, $\times 120$.

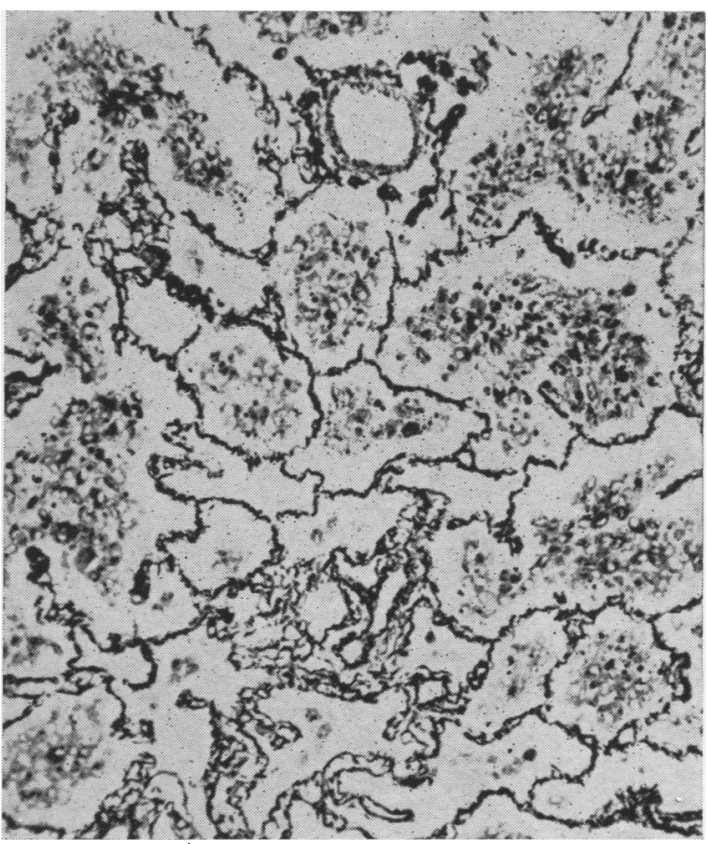

FIG. 5.-Slight thickening of the reticulin framework of the alveoli can be seen, but there is no organization of the intraalveolar exudate. Silver impregnation of reticulin fibres (Gordon and Sweet), $\times 120$. 
TABLE I

CERTAIN DATA ON 16 CASES OF IDIOPATHIC PULMONARY HAEMOSIDEROSIS DIAGNOSED OVER THE AGE OF 14

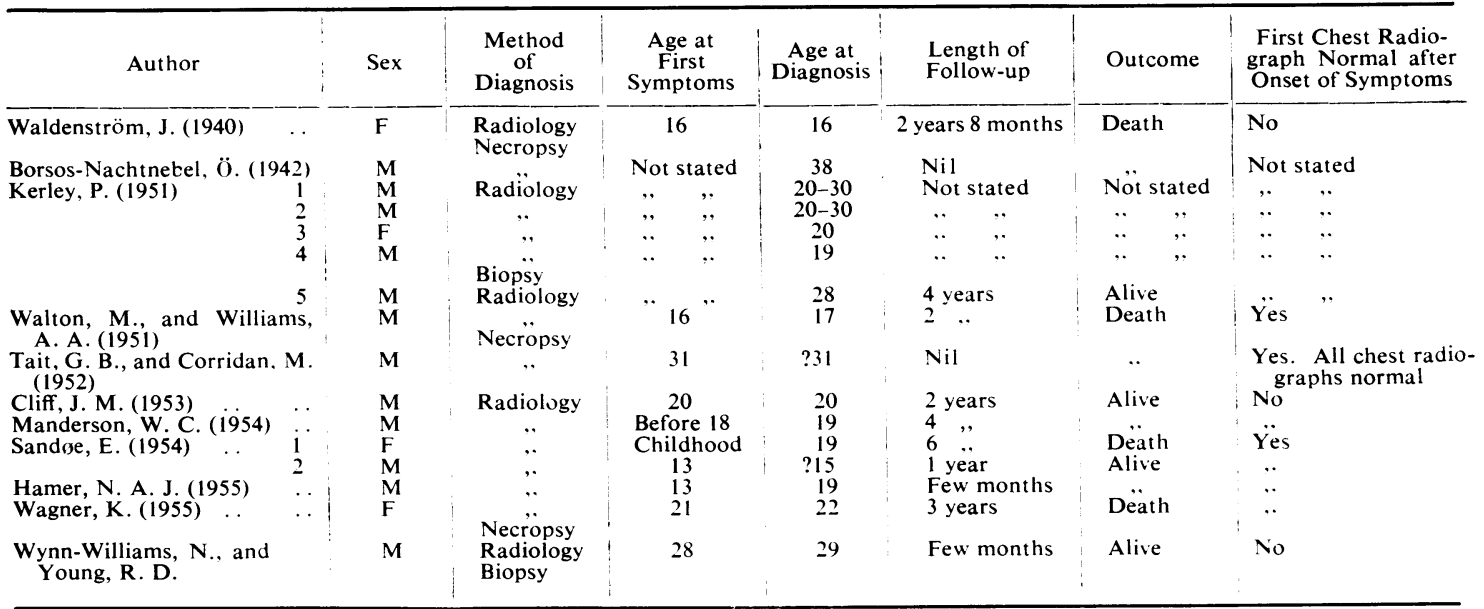

lished cases would suggest. Mistaken diagnoses such as that reported by Walton and Williams (1951) must be easy and the absence of radiological signs in the early stages of the illness most confusing. Being thought a rarity the disease is seldom considered in the differential diagnosis of haemoptysis or anaemia or radiological abnormality. Particular difficulty arises as only one of these features may be present. Furthermore, the radiological abnormality may not consist of the typical bilateral small nodular shadows as in the case reported by Wagner (1955) and in a case shown by Rusby (1955).

The histological findings in this case lend no support to the theory that a loss of elastic tissue in the pulmonary capillaries is the causative factor, but it must be remembered that the biopsy was obtained fairly early in the course of the disease. There was no evidence of an allergic diathesis or of circulating antibodies.

\section{SUMMARY}

A case of idiopathic pulmonary haemosiderosis in a man aged 28 is described. Proof by biopsy was obtained. The cases of idiopathic pulmonary haemosiderosis which have been described in those over the age of 14 are reviewed.

Our thanks are due to Dr. J. W. Clegg and Dr. R. C. Hallam for the histological report, and to Mr. D. F. Kemp for the photomicrographs.

\section{REFERENCES}

Borsos-Nachtnebel, Ö. (1942). Zbl. allg. Path. path. Anat., 79, 174.

Ceelen, W. (1931). In Handbuch der speziellen pathologischen Anatomie, ed. Henke, F., and Lubarsch, O., band 3, teil 3, p. 1 . Springer, Berlin.

Cliff, J. M. (1953). Brit. J. Radiol., 26, 102.

Hamer, N. A. J. (1955). Brit. med. J., 1, 1008.

Kerley, P. (1951). In $A$ Text-book of $X$-ray Diagnosis, 2nd ed. edited by S. C. Shanks and P. Kerley, vol. 2, p. 178. Lewis, London.

Manderson, W. C. (1954). Glasg. med. J., 35, 19.

Rusby, N. L. (1955). Paper delivered at the British Tuberculosi Association Annual Conference, Cambridge.

Sandoe, E. (1954). Danish med. Bull., 1. 175.

Tait, G. B., and Corridan, M. (1952). Thorax, 7, 302.

Wagner, K. (1955). Medizinische, p. 117.

Walton, M., and Williams, A. A. (1951). Brit. med. J., 2, 390.

Waldenström, J. (1940). Nord. Med., 6, 940.

_- (1944). Acta radiol. (Stockh.), 25, 149. 